\title{
MARCOS DE COMPETENCIAS DIGITALES DOCENTES Y SU ADECUACIÓN AL PROFESORADO UNIVERSITARIO Y NO UNIVERSITARIO
}

\author{
Digital Teaching Competences Frameworks and the Suitability of University \\ and Non-university Teachers
}

Julio Cabero-Almenara ${ }^{1}$

cabero@us.es

\section{Rosalía Romero-Tena ${ }^{1}$}

rromero@us.es

\section{Julio Barroso-Osuna ${ }^{1}$}

jbarroso@us.es

\section{Antonio Palacios-Rodríguez} aprodriguez@us.es

${ }^{1}$ Universidad de Sevilla, España

Fecha de recepción: 25/03/2020 Fecha de aprobación: 13/05/2020

\section{Resumen}

Nos encontramos ante la paradoja de la creciente importancia otorgada a las competencias digitales, aunque los datos ponen de manifiesto que una parte importante de la población aún no ha desarrollado estas habilidades básicas. En este artículo nos centraremos en la competencia digital del docente (CDD). Para ello, presentamos una breve panorámica de los principales marcos de referencia para trabajar y mejorar la CDD de profesores universitarios y no universitarios, a partir de los cuales pretendemos conocer si existen diferencias en las valoraciones realizadas por un grupo de expertos sobre los diferentes marcos competenciales. Utilizamos la técnica del juicio de expertos con cálculo de "coeficiente experto". En el estudio participan 335 expertos, los cuales consideran que estos marcos son significativos tanto a nivel universitario como no universitario. De esta forma, se avala la idea de que son propuestas bien consolidadas y que sirven para indicar a los docentes las competencias digitales que deben adquirir para el desempeño de su actividad profesional.

Palabras clave: Competencia Digital Docente, Educación no Universitaria, Educación universitaria, Formación del profesorado, Juicio de expertos.

\section{Abstract}

We are faced with the paradox of the increasing importance given to Digital Competence, although the data shows us that an important part of the population has not yet developed these basic skills. In this article we will focus on the Digital Teacher Competence (DTC), for which we present a brief overview of the main reference frameworks for working and improving the DTC of university and non-university professors, with this we intend to know if there are differences in the evaluations carried out by the experts on the different competence frameworks, using for this the technique of the "Expert Judgment". 335 experts participated in the study, scoring positively the different competency frameworks, endorsing the idea that they are well-consolidated proposals and that they serve to indicate teachers the digital competences they must acquire in order to carry out their professional activity.

Keywords: Digital Teacher Competition, expert judgment, Teacher training, Non-university education, University education. 


\section{Introducción}

En la sociedad del conocimiento, una de las competencias principales es la digital, y se define como aquella que "entraña el uso seguro y crítico de las tecnologías de la sociedad de la información para el trabajo, el ocio y la comunicación" (Consejo de la Unión Europea, 2006, p. 6, 2018, p. 9). Pero los datos muestran que el $44 \%$ de los europeos aún no han desarrollado estas habilidades básicas, a pesar de que el $79 \%$ de los europeos se conectan regularmente en línea, al menos una vez por semana (Joint Research Centre, 2018). Para ser competente digital se ha de ser capaz de solventar los obstáculos propios de la época en la que estamos, "una combinación de conocimientos, capacidades y actitudes adecuadas al contexto" (Consejo de la Unión Europea, 2006, p. 2, 2018, p. 7).

Todo apunta a que la mayoría de los futuros puestos de trabajo necesitarán habilidades digitales (Williamson et al., 2019). Por tanto, la capacidad de usar la tecnología para vivir, trabajar y aprender a lo largo de la vida se debe considerar como un tema transversal a la hora de desarrollar un programa educativo (Romero-Martín \& Fraile-Aranda, 2017). De ahí que la formación docente se considera de vital importancia en diferentes contextos internacionales (Casillas \& Ramírez, 2019; Rodríguez-García et al., 2019; Saavedra et al., 2019; Suárez-Rodríguez et al., 2018).

Dos proyectos de investigación han dado origen a este artículo:

- Diseño, producción y evaluación de tMOOC para la adquisición por los docentes de competencias digitales docentes (RTI2018-097214B-C31).

- Diseño, producción y evaluación de tMOOC para la adquisición de competencias digitales del profesorado universitario (US-1260616).

Su finalidad es la creación y evaluación de un entorno formativo que se encuentra bajo la arquitectura tMOOC, para la capacitación del profesorado universitario y no universitario en la adquisición de competencias digitales docentes. Por este motivo, es necesario seleccionar los estándares de competencia digital docente que más se adecuan actualmente a los diferentes contextos. En este artículo se hace una breve panorámica de los principales marcos de referencia para trabajar y mejorar las competencias digitales docentes, marcos que combinan capacidades profesionales, pedagógicas, tecnológicas y organizativas (Blau \& Shamir-Inbal, 2017; Cuartero et al., 2019; Kullaslahti et al., 2019; Mishra et al., 2006; Porat et al., 2018).

\section{Marcos de competencia digital docente}

De forma general, se puede entender la competencia digital docente (CDD) como aquel conjunto de conocimientos, habilidades y estrategias propias de la profesión docente que permiten solucionar los problemas y retos educativos que plantea la denominada sociedad del conocimiento (Cabero \& Palacios, 2020; Prendes \& Gutiérrez, 2013; Rodríguez-García, et al., 2019).

A lo largo de más de una década, diferentes organizaciones e instituciones han intentado definir los indicadores o estándares que consideran imprescindibles en la competencia digital docente. En este artículo se han seleccionado aquellos marcos que, según diferentes autores, son los más utilizados en el contexto internacional (Cabero \& Martínez, 2019; Cabero \& Palacios, 2020; Durán et al., 2016; Lázaro-Cantabrana et al., 2019; Marín, 2017; Padilla-Hernández et al., 2019; Prendes \& Gutiérrez, 2013; Rodríguez-García et al., 2019; Silva et al., 2019). En las cuatro propuestas que se presentan, se clasifican las competencias en dimensiones y descriptores que los docentes deben desarrollar (McCloskey, 2012).

\subsection{Marco Europeo de Competencia Digital del Profesorado (DigCompEdu) (M1)}

En primer lugar, presentamos el Marco Europeo de Competencia Digital del Profesorado (DigCompEdu), diseñado por el Centro Común de Investigación de la Unión Europea o JRC (Redecker \& Punie, 2017) a finales del año 2017, con el fin de que las políticas educativas europeas tengan dicho marco como 
referencia. Es producto de una serie de estudios científicos realizados a nivel local, nacional, europeo e internacional (Ghomi \& Redecker, 2018; Redecker $\&$ Punie, 2017). DigCompEdu es un modelo de competencia digital con seis áreas competenciales diferenciadas (Figura 1). Cada área lleva asociada una serie de competencias que "los docentes deben poseer para fomentar estrategias de aprendizaje efectivas, inclusivas e innovadoras, utilizando herramientas digitales" (Redecker \& Punie, 2017, p. 4). Son las siguientes:

1. Compromiso profesional: se centra en el entorno de trabajo de los docentes.

2. Recursos digitales: relacionada con las fuentes, la creación y distribución de recursos digitales.
3. Pedagogía digital: la competencia fundamental de todo el marco DigCompEdu es saber diseñar, planificar e implementar el uso de tecnologías digitales en las diferentes etapas del proceso de enseńanza y aprendizaje.

4. Evaluación y retroalimentación: vinculada al uso de herramientas y estrategias digitales en la evaluación y mejora de los procesos de enseñanza-aprendizaje.

5. Empoderar a los estudiantes: uso de herramientas digitales para el empoderamiento del alumnado.

6. Facilitar la competencia digital de los estudiantes: sobre cómo desarrollar y facilitar la competencia digital del alumnado.

\section{Figura 1. Áreas competenciales y competencias del Marco Europeo de Competencia Digital del Profesorado (DigCompEdu)}

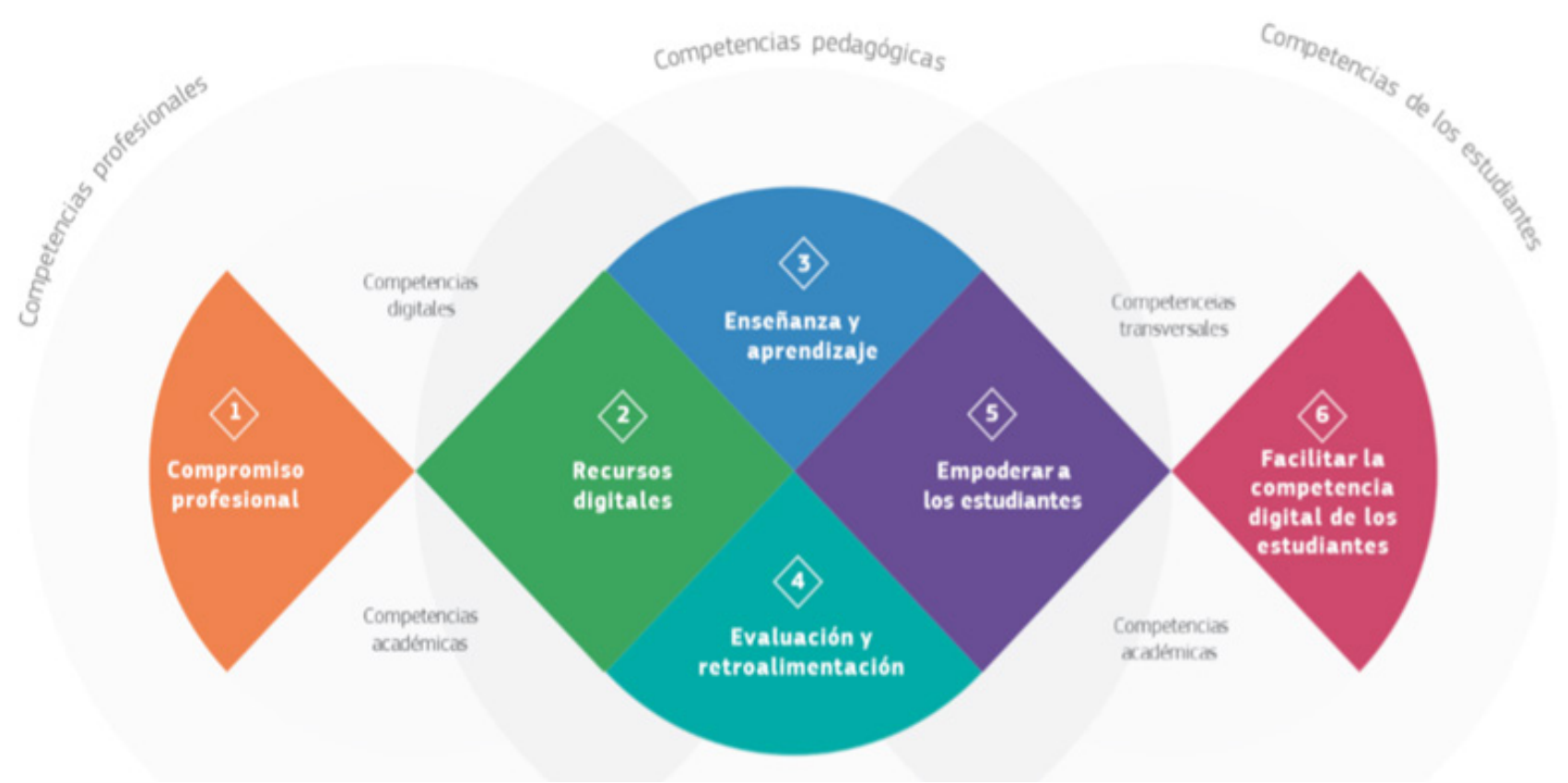

Nota: Extraído de Joint Research Centre (JCR). 
A su vez, DigCompEdu propone seis niveles en función de la cualificación competencial (Figura 2). El nivel más básico es Novato (A1), que correspondería al profesorado con muy poca experiencia y contacto con la tecnología educativa, y el más alto es Pionero (C2), en el que se encontraría el profesorado que lidera la innovación con TIC.

\section{Figura 2. Niveles y progresión competencial del Marco Europeo de Competencia Digital del Profesorado (DigCompEdu)}

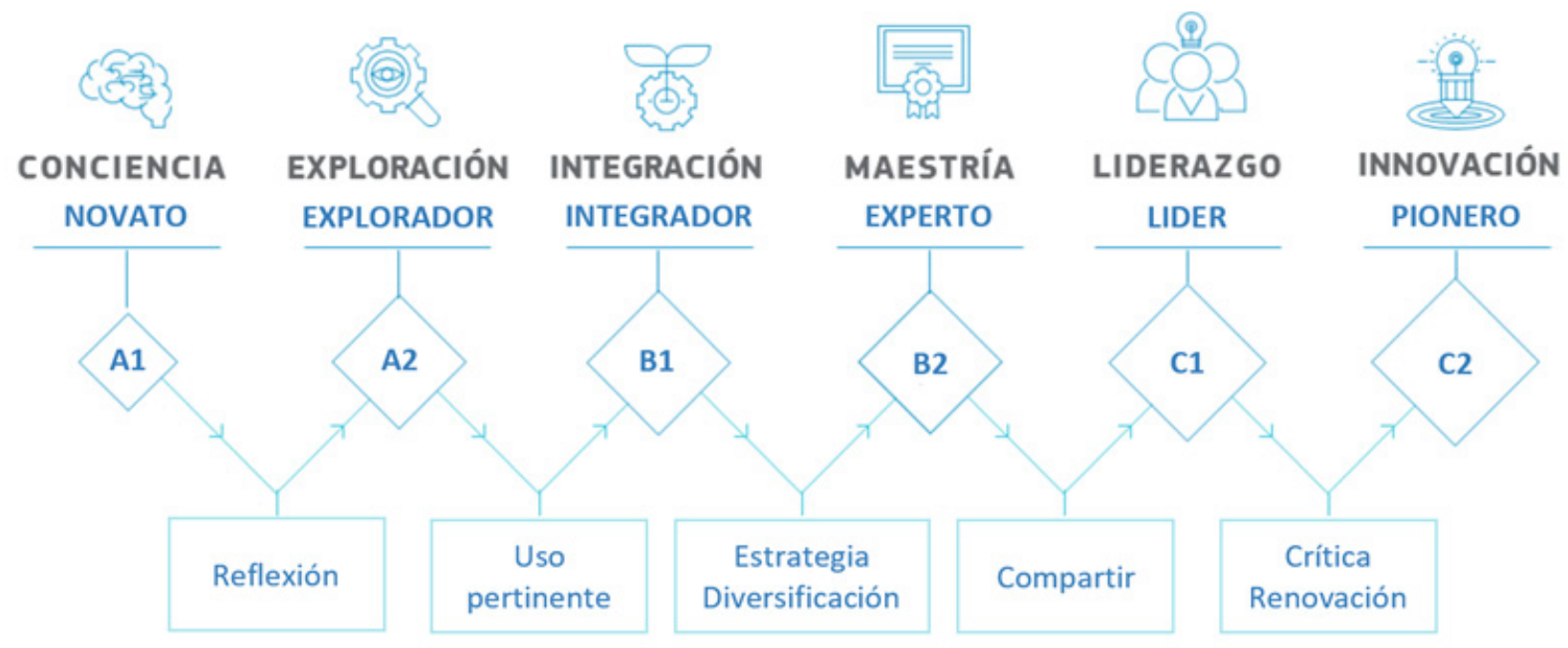

Nota: Elaboración propia.

\subsection{Estándares ISTE para Educadores (M2)}

En esta ocasión, es la Sociedad Internacional de Tecnología en Educación la que desarrolla este marco competencial poniendo su foco de reflexión en las necesidades del alumnado del siglo XXI (Crompton, 2017). El objetivo es profundizar en la práctica docente, promover la colaboración de los estudiantes, repensar los enfoques tradicionales e impulsar el aprendizaje autónomo (ISTE, 2018; Pérez-Escoda et al., 2019). El perfil docente presentado se caracteriza por ser activo e innovador en el proceso de enseñanza-aprendizaje (Gutiérrez-Castillo et al., 2017). Los Estándares ISTE para Educadores constan de siete roles o perfiles que un docente debe desarrollar a lo largo de su carrera profesional.

1. Aprendices: Los docentes mejoran continuamente su práctica aprendiendo de otros y con otros y explorando prácticas que aprovechan la tecnología para mejorar el aprendizaje de los estudiantes.

2. Líderes: Búsqueda de oportunidades de liderazgo para apoyar el empoderamiento y el éxito de los estudiantes, mejorando sus prácticas de enseńanza-aprendizaje.

3. Ciudadanos: Los docentes inspiran a los estudiantes a contribuir positivamente y participar responsablemente en el mundo digital.

4. Colaboradores: Colaboración con los compañeros y estudiantes para mejorar la práctica, descubrir y compartir recursos e ideas y resolver problemas usando las TIC.

5. Diseñadores: Diseño de actividades y entornos con TIC que se adaptan a las necesidades del alumnado.

6. Facilitadores: Facilitar el aprendizaje con tec- 
nología para que el alumnado desarrolle competencias digitales.

7. Analistas: Evaluación y uso de datos para mejorar la docencia y ayudar al alumnado a alcanzar sus objetivos de aprendizaje.

Figura 3. Perfiles docentes según los estándares ISTE para Educadores

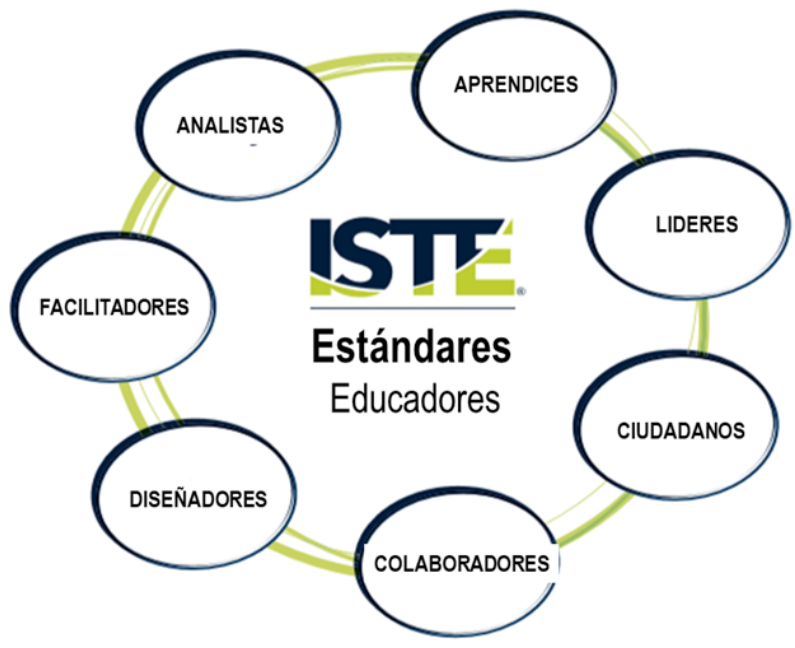

Nota: Elaboración propia.

\subsection{Marco UNESCO de Competencia TIC para Docentes (M3)}

La Organización de las Naciones Unidas para la Educación, la Ciencia y la Cultura también propone "un amplio abanico de competencias que los docentes necesitan para integrar las TIC en su práctica profesional” (Butcher, 2019, p. 2). En este marco se hace hincapié en los beneficios del conocimiento práctico que aportan las TIC a la educación. Recalca que el profesorado, además de adquirir competencias relativas a las TIC, debe poder utilizarlas para ayudar al alumnado a convertirse en ciudadanos colaborativos, creativos, innovadores, comprometidos y resolutivos (Moreno-Rodríguez et al., 2018). Esta propuesta presenta seis áreas o aspectos fundamentales de la práctica profesional docente (Figura 4).
Figura 4. Aspectos fundamentales del Marco UNESCO de Competencia TIC para docentes

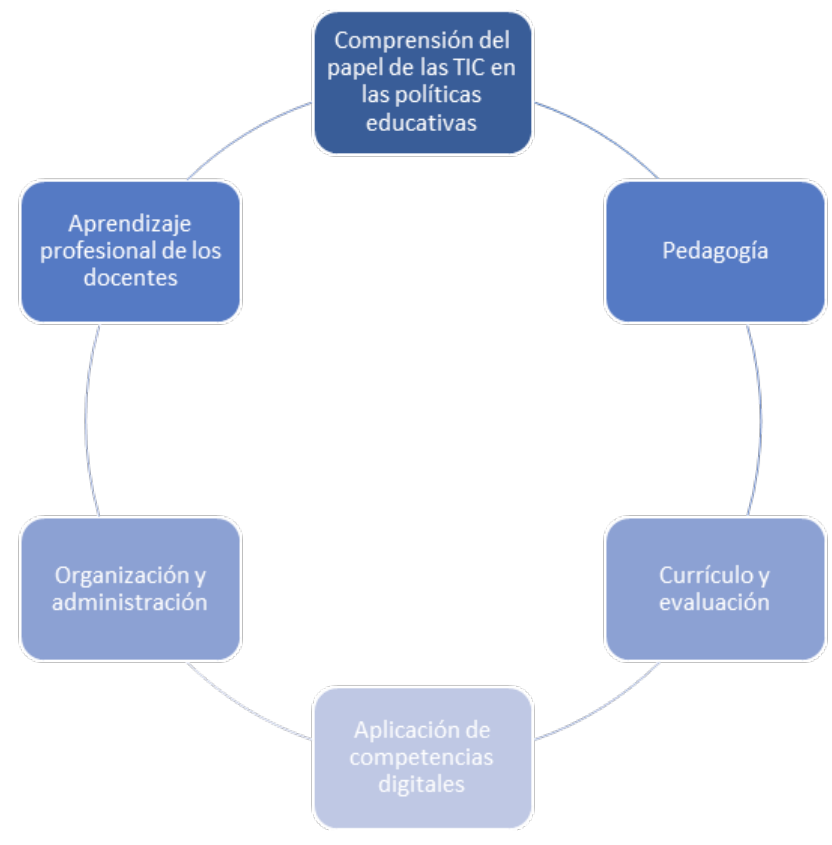

Nota: Elaboración propia.

\subsection{Marco Común español de Competencia Digital Docente (M4)}

Para diseñar el Marco Común español de Competencias Digital Docente se toma como base el Marco de Competencia Digital para Ciudadanos DigComp (Carretero et al., 2017; Ferrari, 2013; Vuorikari et al., 2016). Este marco fue elaborado por el Ministerio de Educación, Cultura y Deporte de Espańa y comienza un proyecto para la definición del Marco Común de Competencia Digital Docente, actualizado en cuatro ocasiones (INTEF, 2013, 2014, 2017a, $2017 b)$. Se trata de un modelo de competencia digital genérica para formadores. Las áreas competenciales (5) y competencias (21) son las mismas que las del marco DigComp: información y alfabetización informacional, comunicación y colaboración, creación de contenidos digitales, seguridad y resolución de problemas. El nivel progresivo de autonomía y desarrollo comienza desde el nivel A1 y continúa hasta el nivel máximo, C2. Dichas áreas son las siguientes:

1. Información y alfabetización informacional: identificar, localizar, recuperar, almacenar, organizar y analizar la información digital, eva- 
luando su finalidad y relevancia.

2. Comunicación y colaboración: comunicar en entornos digitales, compartir recursos a través de herramientas en línea, conectar y colaborar con otros a través de herramientas digitales, interactuar y participar en comunidades y redes; conciencia intercultural.

3. Creación de contenido digital: crear y editar contenidos nuevos (textos, imágenes, videos...), integrar y reelaborar conocimientos y contenidos previos, realizar producciones artísticas, contenidos multimedia y programación informática, saber aplicar los derechos de propiedad intelectual y las licencias de uso.

4. Seguridad: protección personal, protección de datos, protección de la identidad digital, uso de seguridad, uso seguro y sostenible.

5. Resolución de problemas: identificar necesidades y recursos digitales, tomar decisiones a la hora de elegir la herramienta digital apropiada, acorde a la finalidad o necesidad, resolver problemas conceptuales a través de medios digitales, resolver problemas técnicos, uso creativo de la tecnología, actualizar la competencia propia y la de otros.

\section{Figura 5. Áreas del Marco Común de Competencia Digital Docente}

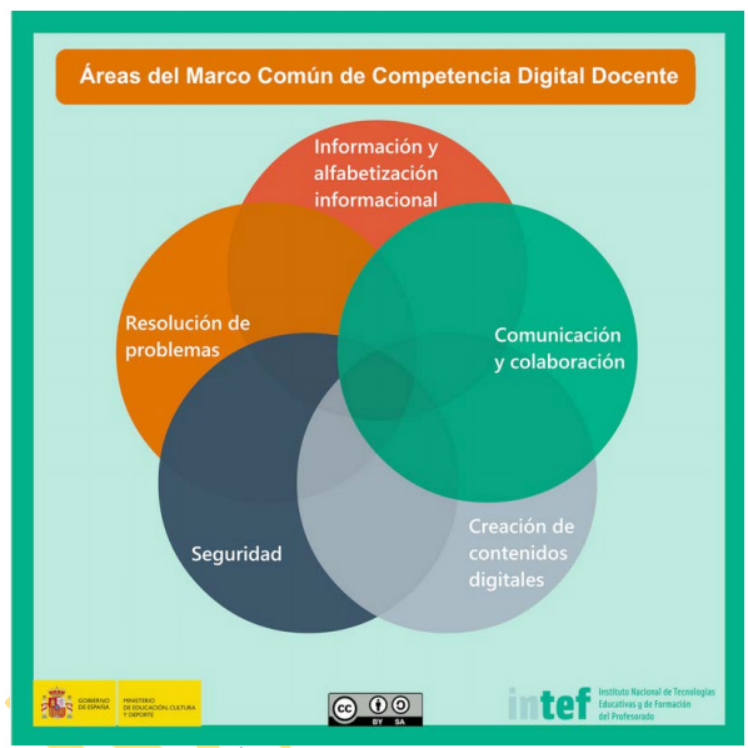

\subsection{Marco británico de Enseñanza Digital (M5)}

Siguiendo en la línea que hemos iniciado, corresponde hacer una breve descripción del Marco británico de Enseńanza Digital diseńado por la Fundación para la Educación y la Enseńanza (ETF) y la empresa Education and Training Foundation (JISC) en 2019. El objetivo es aumentar la comprensión sobre cómo los docentes pueden usar las tecnologías digitales para enriquecer sus prácticas de enseñanza y mejorar su desarrollo profesional (Pérez-Escoda et al., 2019). En este marco nos encontramos con siete áreas y tres niveles (exploración, adaptación y líder). Las siete áreas son las siguientes:

1. Planificación Pedagógica: usar la tecnología digital para ayudar en los procesos de enseñanza-aprendizaje.

2. Enfoque Pedagógico: usar recursos digitales para involucrar a los alumnos en el aprendizaje presencial, mixto y en línea.

3. Empleabilidad del Alumnado: usar tecnologías digitales para mejorar las perspectivas de empleo del alumnado.

4. Enseñanza Específica: desarrollar el conocimiento específico de la asignatura y actitud emprendedora del alumnado a través de la tecnología.

5. Evaluación: usar la tecnología digital para mejorar la evaluación y proporcionar retroalimentación.

6. Accesibilidad e Inclusión: garantizar que todo el alumnado pueda beneficiarse de la tecnología digital.

7. Autodesarrollo: reflexionar sobre la práctica profesional, desarrollando la competencia digital y promoviendo una identidad digital segura. 


\subsection{Competencias TIC para el desarrollo profesional docente colombiano (M6)}

El Ministerio de Educación Nacional (MEN) de Colombia diseñó un marco para guiar el proceso de desarrollo profesional docente para la mejora de la innovación educativa con TIC (Fernanda et al., 2013). Está enfocado tanto en diseńadores de programas formativos como en docentes interesados en generar ambientes enriquecidos con las TIC (Hernández Suárez, 2016). Este marco define cinco competencias que deben desarrollar los docentes: tecnológica, pedagógica, comunicativa, investigación y gestión, dentro de tres niveles específicos de innovación educativa con TIC (explorador, integrador e innovador) (Figura 6).

Figura 6. Competencias y niveles del marco colombiano de competencias TIC para el desarrollo profesional docente.

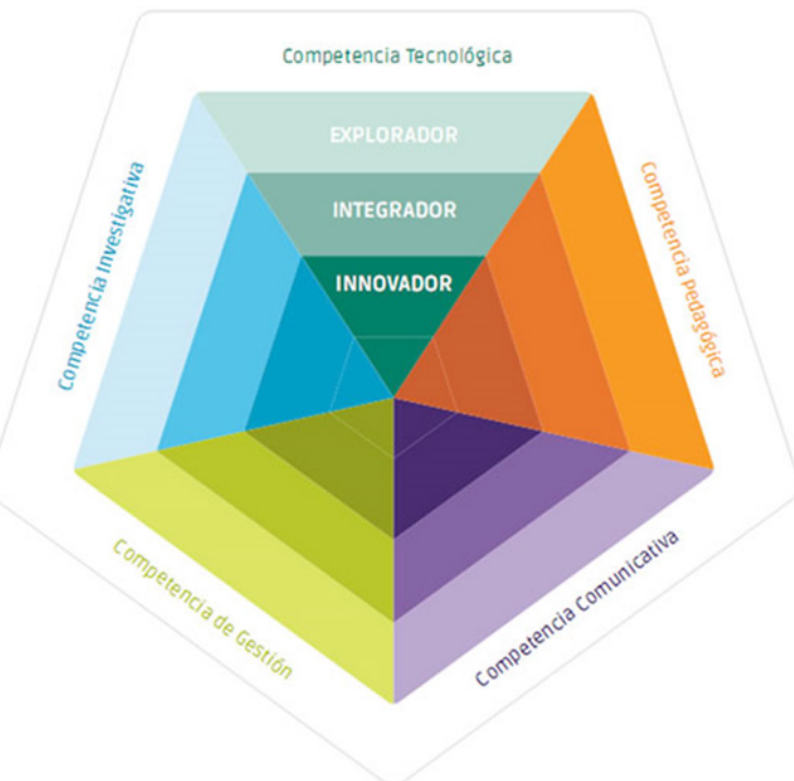

Nota: Extraído del Ministerio de Educación Nacional de Colombia (2013)

\subsection{Competencias y Estándares TIC para la profesión docente en Chile (M7)}

Para finalizar, exponemos el marco elaborado por el Centro de Educación y Tecnología del Ministerio de Educación chileno publicado en 2011, tras realizar una serie de actualizaciones del modelo anterior de 2006 (Elliot et al., 2011). Presenta cinco dimensiones, a saber: pedagógica, técnica, desarrollo y responsabilidad, social, ética y legal, y gestión (Figura 7); estas dimensiones están en sintonía con el Marco UNESCO de Competencia TIC para Docentes (Butcher, 2019).

Figura 7. Estructura del Marco de Competencias y Estándares TIC para la profesión docente en Chile

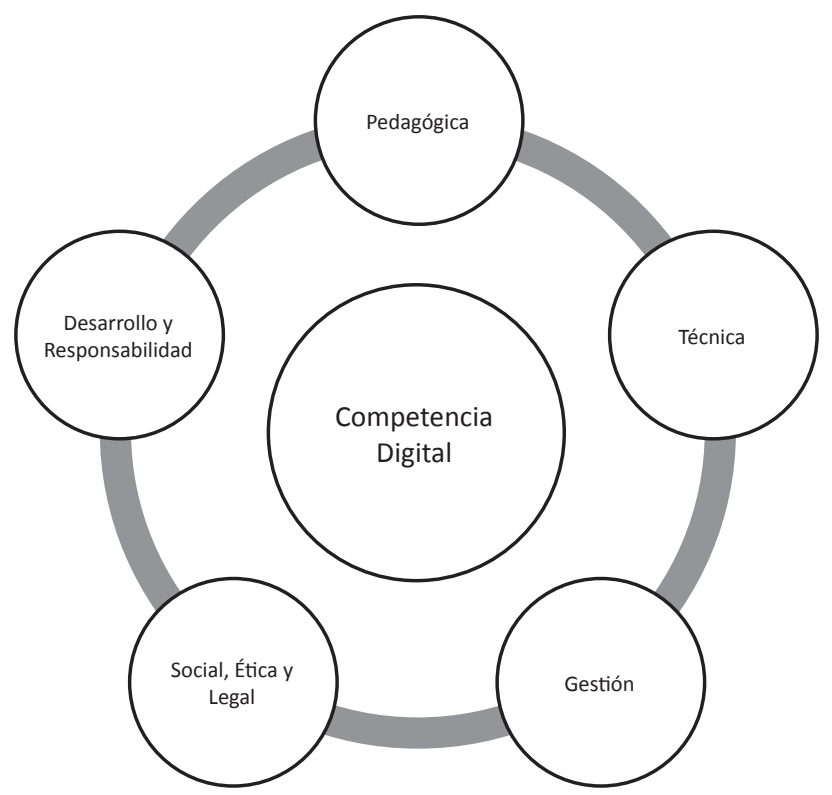

Nota: Elaboración propia.

Todos los marcos referidos tienen en común el hecho de que trabajan competencias, criterios y descriptores y perfilan cada estándar para identificar la manera en que se pueden usar e integrar las TIC, identificar sus necesidades formativas y definir itinerarios formativos personalizados (Flores-Lueg \& Roig Vila, 2016).

\section{La investigación}

La investigación sobre las competencias digitales de los docentes puede hacerse desde diferentes perspectivas, dos de ellas pueden ser las siguientes: qué marcos competenciales son más adecuados y funcionales para la capacitación de los docentes en CDD, y cuál 
es el grado de pertinencia de los diferentes niveles competenciales reflejados en los marcos.

En esta investigación, el objetivo que se persigue es saber si hay diferencias en las valoraciones de jueces expertos sobre diferentes marcos competenciales, de acuerdo con su adecuación para docentes de niveles universitarios y no universitarios, o si los jueces dictaminan que tales marcos son necesarios para los docentes, independientemente del nivel en el que realizan su actividad profesional de la enseñanza.

Digamos que la técnica del "Juicio de Expertos" (Cabero \& Llorente, 2013; Galicia et al., 2017; Robles \& Rojas, 2015) es de gran utilidad para solicitar a una serie de personas cualificadas "a priori” que emitan una valoración respecto de un objeto, instrumento, material de enseñanza o aspecto concreto, como será nuestro caso. Su eficacia depende del proceso que se siga para la selección de los jueces.

En el presente estudio, se seleccionaron expertos que cumplieran dos o más de los siguientes criterios:

1. Tener experiencia como profesor de alguna de las siguientes asignaturas: Tecnología Educativa, Nuevas Tecnologías aplicadas a la Educación, o Tecnologías de la Información y Comunicación Aplicadas a la Educación.

2. Tener experiencia en el terreno de la formación del profesorado en TIC y haber publicado algún artículo sobre las siguientes áreas del saber: alfabetización en tecnología educativa, competencias digitales, alfabetización audiovisual, en revistas españolas y latinoamericanas, en los últimos cinco años.

3. Haber asistido a alguno de los últimos tres congresos de Edutec o CITEI (eventos internacionales centrados en la aplicación educativa de las TIC).
4. Haber colaborado con investigadores en algún proyecto de investigación relacionado con la incorporación de las TIC.

Además, se procede a aplicar el coeficiente de competencia experta (CCE) para la selección definitiva (Cabero \& Barroso, 2013; Cabero \& Infante, 2014; López-Gómez, 2018), coeficiente que se obtiene por medio de las preguntas ubicadas en el Anexo. En el Anexo también se especifican los parámetros y criterios que los expertos tuvieron en cuenta para valorar los marcos competenciales.

Para la obtención del citado coeficiente se aplica la fórmula: $K=1 / 2(K c+K a)$. Donde $K c$ es el coeficiente de conocimiento, y se obtiene de la puntuación ofrecida directamente por el experto en la pregunta A del Anexo, y Ka es el coeficiente de argumentación, que se alcanza sumando las opciones especificadas por el experto en la tabla de la pregunta B del Anexo.

El número de correos electrónicos, de acuerdo con los criterios inicialmente tenidos en cuenta, que se mandaron a expertos para que colaboraran en la investigación fue de 335 para los que evaluarían los marcos respecto a su adaptación para el contexto universitario, y de 412 para los universitarios. De los primeros recibimos 183 respuestas y de los segundos, 152. En ambos casos, el tiempo que se les dio para su cumplimentación fue de dos semanas.

Los valores que se utilizan para determinar la posición del experto son:

$-0.8<\mathrm{K}<1.0$ : coeficiente de competencia alto

$-0.5<\mathrm{K}<0.8$ : coeficiente de competencia medio

- K < 0.5: coeficiente de competencia bajo

En la Tabla 1 se presentan algunas de las características de los jueces que participaron en la evaluación de ambos instrumentos. 
Tabla 1. Características demográficas de los jueces

\begin{tabular}{|c|c|c|c|c|c|}
\hline & \multicolumn{5}{|c|}{ Nivel } \\
\hline & \multicolumn{2}{|c|}{ No universitario } & \multicolumn{2}{|c|}{ Universitario } & \\
\hline & $f$ & $\%$ & $f$ & $\%$ & \\
\hline \multirow[t]{5}{*}{ Titulación } & Doctorado & 88 & 73.9 & 130 & 83.3 \\
\hline & Máster & 21 & 17.6 & 26 & 16.7 \\
\hline & Grado o licenciatura & 4 & 3.4 & 0 & 0.0 \\
\hline & Licenciatura & 2 & 1.7 & 0 & 0.0 \\
\hline & Diplomatura & 4 & 3.4 & 0 & 0.0 \\
\hline \multirow{2}{*}{$\begin{array}{l}\text { Trabaja en un centro universi- } \\
\text { tario }\end{array}$} & Sí & 86 & 72.3 & 148 & 94.9 \\
\hline & No & 33 & 27.7 & 8 & 5.1 \\
\hline \multirow{2}{*}{$\begin{array}{l}\text { Trabaja en un centro no univer- } \\
\text { sitario }\end{array}$} & Sí & 27 & 22.7 & 4 & 2.6 \\
\hline & No & 92 & 77.3 & 152 & 97.4 \\
\hline \multirow{2}{*}{$\begin{array}{l}\text { Trabaja en una empresa de } \\
\text { formación }\end{array}$} & Sí & 10 & 8.4 & 6 & 3.8 \\
\hline & No & 109 & 91.6 & 150 & 96.2 \\
\hline \multirow{2}{*}{$\begin{array}{l}\text { Trabaja en una empresa de } \\
\text { tecnología }\end{array}$} & Sí & 2 & 1.7 & 2 & 1.3 \\
\hline & No & 117 & 98.3 & 154 & 98.7 \\
\hline \multirow[t]{2}{*}{ Docente } & Sí & 110 & 92.4 & 153 & 98.1 \\
\hline & No & 9 & 7.6 & 3 & 1.9 \\
\hline \multirow[t]{2}{*}{ Técnica } & Sí & 15 & 12.6 & 11 & 7.1 \\
\hline & No & 104 & 87.4 & 145 & 92.9 \\
\hline \multirow[t]{2}{*}{ Gestión } & Sí & 35 & 29.4 & 41 & 26.3 \\
\hline & No & 84 & 70.6 & 115 & 73.7 \\
\hline \multirow[t]{2}{*}{ Clases de tecnología educativa } & Sí & 113 & 95.0 & 151 & 96.8 \\
\hline & No & 6 & 5.0 & 5 & 3.2 \\
\hline \multirow{2}{*}{$\begin{array}{l}\text { Investigación de tecnología } \\
\text { educativa }\end{array}$} & Sí & 112 & 94.1 & 153 & 98.1 \\
\hline & No & 7 & 5.9 & 3 & 1.9 \\
\hline \multirow{2}{*}{$\begin{array}{l}\text { Publicaciones de tecnología } \\
\text { educativa }\end{array}$} & Sí & 104 & 87.4 & 153 & 98.1 \\
\hline & No & 15 & 12.6 & 3 & 1.9 \\
\hline \multirow{2}{*}{$\begin{array}{l}\text { Clases de competencias digi- } \\
\text { tales }\end{array}$} & Sí & 114 & 95.8 & 150 & 96.2 \\
\hline & No & 5 & 4.2 & 6 & 3.8 \\
\hline
\end{tabular}

Nota: Elaboración propia.

Como podemos observar, todos los expertos que tienen una valoración superior a 0.8 . indican que poseen experiencia de docencia y han participado en publicaciones e investigaciones sobre las TIC y la competencia y alfabetización digital del profesorado. En síntesis, los expertos quedaron conformados por docentes de diferentes niveles educativos y personal técnico.
Hay que señalar que los marcos competenciales evaluados fueron los siguientes:

1. Marco de la Unión Europea de Competencia digital Docente (M1).

2. Marco de la International Society for Technology in Education (ISTE) para docentes (M2).

3. Marco UNESCO de Competencia TIC para Docentes (M3). 
4. Marco común de competencia digital docente del Instituto Nacional de Tecnología Educativa y de Formación del Profesorado (INTEF) (M4).

5. Marco de enseñanza digital del Reino Unido (M5).

6. Competencias TIC para el desarrollo profesional docente del Ministerio de Educación Nacional de Colombia (M6).

7. Competencias y estándares TIC para la profesión docente del Ministerio de Educación de Chile (M7).

Estos marcos son los más utilizados en el contexto internacional (Cabero \& Martínez, 2019; Cabero
\& Palacios, 2020; Durán et al., 2016; Lázaro-Cantabrana et al., 2019; Marín, 2017; Padilla-Hernández et al., 2019; Prendes \& Gutiérrez, 2013; Rodríguez-García et al., 2019; Silva et al., 2019;).

El instrumento se administró vía internet (Google Forms).

\section{Resultados obtenidos}

Comencemos presentando las medias y desviaciones típicas de cada marco, de forma global, como de cada una de las dimensiones (Tabla 2). Para interpretar correctamente las puntuaciones se debe tener en cuenta que la escala de respuesta iba desde $1=\mathrm{MN}$ $=$ Muy negativo/muy en desacuerdo hasta $6=\mathrm{MP}=$ Muy positivo/Muy de acuerdo.

Tabla 2. Medias y desviaciones típicas de los diferentes marcos

\begin{tabular}{|c|c|c|c|c|}
\hline \multirow{2}{*}{$\begin{array}{l}\text { MARCO COMPETENCIAL } \\
\text { Marco europeo de competencia digital del profesorado (Unión Euro- } \\
\text { pea) }\end{array}$} & \multicolumn{2}{|c|}{ No Univ. } & \multicolumn{2}{|c|}{ Univ. } \\
\hline & $\mathbf{M}$ & D.t. & $\mathbf{M}$ & D.t. \\
\hline $\begin{array}{l}\text { Compromiso profesional: Capacidad para utilizar las tecnologías digitales } \\
\text { no solo para mejorar la enseñanza, sino también para interaccionar profe- } \\
\text { sionalmente con compañeros, alumnado, familia y distintos agentes de la } \\
\text { comunidad educativa. Además, esta comunicación a través de la tecnolo- } \\
\text { gía permite el desarrollo profesional individual y la innovación colectiva y } \\
\text { continua en la organización educativa. }\end{array}$ & 5.69 & 0.55 & 5.65 & 0.55 \\
\hline $\begin{array}{l}\text { Recursos digitales: Identificar buenos recursos educativos. Además, debe } \\
\text { ser capaz de modificarlos, crearlos y compartirlos para que se ajusten a } \\
\text { sus objetivos, alumnado y estilo de enseñanza. Al mismo tiempo, debe } \\
\text { saber cómo usar y administrar de manera responsable el contenido digi- } \\
\text { tal, respetando las normas de derechos de autor y protegiendo los datos } \\
\text { personales. }\end{array}$ & 5.70 & 0.48 & 5.65 & 0.63 \\
\hline $\begin{array}{l}\text { Pedagogía digital: Saber diseñar, planificar e implementar el uso de tec- } \\
\text { nologías digitales en las diferentes etapas del proceso de enseñanza y } \\
\text { aprendizaje. Además, se aboga por un cambio de enfoques y metodolo- } \\
\text { gías que estén centradas en el alumnado. }\end{array}$ & 5.67 & 0.57 & 5.68 & 0.59 \\
\hline $\begin{array}{l}\text { Evaluación y retroalimentación: Las tecnologías digitales pueden mejorar } \\
\text { las estrategias de evaluación existentes y dar lugar a nuevos y mejores } \\
\text { métodos de evaluación. Además, al analizar la gran cantidad de datos } \\
\text { (digitales) disponibles sobre las (inter-) acciones individuales de los estu- } \\
\text { diantes, los docentes pueden ofrecer comentarios y apoyos más específi- } \\
\text { cos. }\end{array}$ & 5.52 & 0.72 & 5.52 & 0.63 \\
\hline
\end{tabular}




\begin{tabular}{|c|c|c|c|c|}
\hline \multirow{2}{*}{$\begin{array}{l}\text { MARCO COMPETENCIAL } \\
\text { Marco europeo de competencia digital del profesorado (Unión Euro- } \\
\text { pea) }\end{array}$} & \multicolumn{2}{|c|}{ No Univ. } & \multicolumn{2}{|c|}{ Univ. } \\
\hline & $\mathbf{M}$ & D.t. & $\mathbf{M}$ & D.t. \\
\hline $\begin{array}{l}\text { Empoderar a los estudiantes: Una de las fortalezas clave de las tecnolo- } \\
\text { gías digitales en la educación es su potencial para impulsar la participa- } \\
\text { ción activa de los estudiantes en el proceso de aprendizaje y su autono- } \\
\text { mía sobre el mismo. Además, las tecnologías digitales se pueden utilizar } \\
\text { para ofrecer actividades de aprendizaje adaptadas al nivel de competen- } \\
\text { cia de cada estudiante, sus intereses y necesidades de aprendizaje. Sin } \\
\text { embargo, se debe tener cuidado de no exacerbar las desigualdades exis- } \\
\text { tentes (por ejemplo, en el acceso a las tecnologías digitales) y asegurar la } \\
\text { accesibilidad para todos los estudiantes, incluidos aquellos con necesida- } \\
\text { des especiales de aprendizaje. }\end{array}$ & 5.52 & 0.72 & 5.58 & 0.64 \\
\hline $\begin{array}{l}\text { Facilitar la competencia digital de los estudiantes: La capacidad de fa- } \\
\text { cilitar la competencia digital de los estudiantes es una parte integral de } \\
\text { la competencia digital de los docentes y es la principal temática de esta } \\
\text { área de competencias. Las opciones de respuesta están organizadas por } \\
\text { distintos niveles de compromiso con las tecnologías digitales. }\end{array}$ & 5.70 & 0.53 & 5.61 & 0.57 \\
\hline TOTAL ESCALA & 5.63 & 0.39 & 5.62 & 0.41 \\
\hline \multicolumn{5}{|l|}{ Estándares ISTE para docentes } \\
\hline $\begin{array}{l}\text { Aprendices: Los docentes mejoran continuamente su práctica aprendien- } \\
\text { do de otros y con otros y explorando prácticas que aprovechan la tecnolo- } \\
\text { gía para mejorar el aprendizaje de los estudiantes. }\end{array}$ & 5.37 & 0.71 & 5.33 & 0.75 \\
\hline $\begin{array}{l}\text { Líderes: Los docentes buscan oportunidades de liderazgo para apoyar el } \\
\text { empoderamiento y el éxito de los estudiantes, mejorando sus prácticas de } \\
\text { enseñanza-aprendizaje. }\end{array}$ & 5.15 & 0.95 & 5.06 & 0.88 \\
\hline $\begin{array}{l}\text { Ciudadanos: Los docentes inspiran a los estudiantes a contribuir positiva- } \\
\text { mente y participar responsablemente en el mundo digital. }\end{array}$ & 5.36 & 0.787 & 5.36 & 0.85 \\
\hline $\begin{array}{l}\text { Colaboradores: Los docentes dedican tiempo a colaborar con sus compa- } \\
\text { ñeros y estudiantes para mejorar la práctica, descubrir y compartir recur- } \\
\text { sos e ideas y resolver problemas usando las TIC. }\end{array}$ & 5.29 & 0.76 & 5.27 & 0.81 \\
\hline $\begin{array}{l}\text { Diseñadores: Los docentes diseñan actividades y entornos con TIC que } \\
\text { se adaptan a las necesidades del alumnado. }\end{array}$ & 5.33 & 0.70 & 5.21 & 0.95 \\
\hline $\begin{array}{l}\text { Facilitadores: Los educadores facilitan el aprendizaje con tecnología para } \\
\text { que el alumnado desarrolle competencias digitales. }\end{array}$ & 5.51 & 0.97 & 5.41 & 0.87 \\
\hline $\begin{array}{l}\text { Analistas: Los educadores entienden y usan datos para mejorar su do- } \\
\text { cencia y ayudar al alumnado a alcanzar sus objetivos de aprendizaje. }\end{array}$ & 5.11 & & 5.10 & 0.92 \\
\hline TOTAL & 5.30 & 0.63 & 5.25 & 0.65 \\
\hline \multicolumn{5}{|l|}{ Marco UNESCO de Competencia TIC para Docentes } \\
\hline $\begin{array}{l}\text { Comprender las TIC en la política educativa: Usar las TIC para apoyar los } \\
\text { objetivos específicos identificados en el currículo y desempeñar un papel } \\
\text { en el apoyo a la evaluación. }\end{array}$ & 5.13 & 0.91 & 5.05 & 0.92 \\
\hline $\begin{array}{l}\text { Currículo y evaluación: Adquirir habilidades con TIC para apoyar métodos } \\
\text { efectivos de enseñanza y aprendizaje. }\end{array}$ & 5.48 & 0.65 & 5.40 & 0.72 \\
\hline $\begin{array}{l}\text { Pedagogía: Uso de las TIC para apoyar métodos efectivos de enseñanza } \\
\text { y aprendizaje. }\end{array}$ & 5.68 & 0.60 & 5.62 & 0.60 \\
\hline
\end{tabular}




\begin{tabular}{|c|c|c|c|c|}
\hline \multirow{2}{*}{$\begin{array}{l}\text { MARCO COMPETENCIAL } \\
\text { Marco europeo de competencia digital del profesorado (Unión Euro- } \\
\text { pea) }\end{array}$} & \multicolumn{2}{|c|}{ No Univ. } & \multicolumn{2}{|c|}{ Univ. } \\
\hline & M & D.t. & M & D.t. \\
\hline $\begin{array}{l}\text { Aplicación de habilidades digitales: Adquirir habilidades con TIC para inte- } \\
\text { grarlas en los procesos de enseñanza-aprendizaje. }\end{array}$ & 5.60 & 0.64 & 5.52 & 0.71 \\
\hline $\begin{array}{l}\text { Organización y administración: Administrar los dispositivos digitales del } \\
\text { centro educativo, así como proteger a las personas que los usan. }\end{array}$ & 5.19 & 0.89 & 5.13 & 0.94 \\
\hline $\begin{array}{l}\text { Aprendizaje profesional: Utilizar la competencia digital en su entorno pro- } \\
\text { fesional. }\end{array}$ & 5.57 & 0.72 & 5.51 & 0.67 \\
\hline TOTAL & 5.13 & 0.90 & 5.37 & 0.56 \\
\hline \multicolumn{5}{|l|}{ Marco común de competencia digital docente del INTEF (España) } \\
\hline $\begin{array}{l}\text { Información y alfabetización informacional: Identificar, localizar, obtener, } \\
\text { almacenar, organizar y analizar información digital, datos y contenidos } \\
\text { digitales, evaluando su finalidad y relevancia para las tareas docentes. }\end{array}$ & 5.51 & 0.68 & 5.44 & 0.74 \\
\hline $\begin{array}{l}\text { Comunicación y colaboración: Comunicar en entornos digitales, compar- } \\
\text { tir recursos a través de herramientas en línea, conectar y colaborar con } \\
\text { otros a través de herramientas digitales, interactuar y participar en comu- } \\
\text { nidades y redes; conciencia intercultural. }\end{array}$ & 5.54 & 0.69 & 5.56 & 0.66 \\
\hline $\begin{array}{l}\text { Creación de contenidos digitales: Crear y editar contenidos digitales nue- } \\
\text { vos, integrar y reelaborar conocimientos y contenidos previos, realizar } \\
\text { producciones artísticas, contenidos multimedia y programación informáti- } \\
\text { ca, saber aplicar los derechos de propiedad intelectual y las licencias de } \\
\text { uso. }\end{array}$ & 5.40 & 0.87 & 5.31 & 0.84 \\
\hline $\begin{array}{l}\text { Seguridad: Protección de información y datos personales, protección de } \\
\text { la identidad digital, protección de los contenidos digitales, medidas de } \\
\text { seguridad y uso responsable y seguro de la tecnología. }\end{array}$ & 5.48 & 0.80 & 5.29 & 0.92 \\
\hline $\begin{array}{l}\text { Resolución de problemas: Identificar necesidades de uso de recursos } \\
\text { digitales, tomar decisiones informadas sobre las herramientas digitales } \\
\text { más apropiadas según el propósito o la necesidad, resolver problemas } \\
\text { conceptuales a través de medios digitales, usar las tecnologías de forma } \\
\text { creativa, resolver problemas técnicos, actualizar su propia competencia y } \\
\text { la de otros. }\end{array}$ & 5.50 & 0.79 & 5.43 & 0.73 \\
\hline TOTAL & 5.49 & 0.57 & 5.41 & 0.59 \\
\hline \multicolumn{5}{|l|}{ Marco de enseñanza digital (Reino Unido) } \\
\hline $\begin{array}{l}\text { Planificación pedagógica: Usar la tecnología digital para ayudar en los } \\
\text { procesos de enseñanza-aprendizaje. }\end{array}$ & 5.48 & 0.72 & 5.62 & 0.56 \\
\hline $\begin{array}{l}\text { Enfoque pedagógico: Usar recursos digitales para involucrar a los alum- } \\
\text { nos en el aprendizaje presencial, mixto y en línea. }\end{array}$ & 5.34 & 0.96 & 5.53 & 0.68 \\
\hline $\begin{array}{l}\text { Empleabilidad del alumnado: Usar tecnologías digitales para mejorar las } \\
\text { perspectivas de empleo del alumnado. }\end{array}$ & 5.09 & 1.02 & 5.28 & 0.90 \\
\hline $\begin{array}{l}\text { Enseñanza específica: Desarrollar el conocimiento específico de la asig- } \\
\text { natura y actitud emprendedora del alumnado a través de la tecnología. }\end{array}$ & 5.02 & 1.10 & 5.08 & 0.87 \\
\hline $\begin{array}{l}\text { Evaluación: Usar la tecnología digital para la mejora de la evaluación y } \\
\text { para proporcionar retroalimentación. }\end{array}$ & 5.34 & 0.86 & 5.36 & 0.72 \\
\hline $\begin{array}{l}\text { Accesibilidad e inclusión: Garantizar que todo el alumnado pueda benefi- } \\
\text { ciarse de la tecnología digital. }\end{array}$ & 5.61 & 0.75 & 5.54 & 0.74 \\
\hline
\end{tabular}


CABERO-ALMENARA • ROMERO-TENA • BARROSO-OSUNA • PALACIOS-RODRÍGUEZ

Marcos de Competencias Digitales Docentes y su adecuación al profesorado universitario...

\begin{tabular}{|c|c|c|c|c|}
\hline \multirow{2}{*}{$\begin{array}{l}\text { MARCO COMPETENCIAL } \\
\text { Marco europeo de competencia digital del profesorado (Unión Euro- } \\
\text { pea) }\end{array}$} & \multicolumn{2}{|c|}{ No Univ. } & \multicolumn{2}{|c|}{ Univ. } \\
\hline & M & D.t. & M & D.t. \\
\hline $\begin{array}{l}\text { Autodesarrollo: Reflexionar sobre la práctica profesional, desarrollando la } \\
\text { competencia digital y promoviendo una identidad digital segura. }\end{array}$ & 5.41 & 0.86 & 5.43 & 0.76 \\
\hline TOTAL & 5.33 & 0.68 & 5.40 & 0.55 \\
\hline \multicolumn{5}{|l|}{ Competencias TIC para el desarrollo profesional docente (Colombia) } \\
\hline $\begin{array}{l}\text { Tecnológica: Seleccionar y utilizar de forma pertinente, responsable y } \\
\text { eficiente una variedad de herramientas tecnológicas entendiendo los } \\
\text { principios que las rigen, la forma de combinarlas y las licencias que las } \\
\text { amparan. }\end{array}$ & 5.32 & 0.77 & 5.62 & 0.56 \\
\hline $\begin{array}{l}\text { Comunicativa: Expresar, establecer contacto y relacionarse en espacios } \\
\text { virtuales y audiovisuales a través de diversos medios y con el manejo de } \\
\text { múltiples lenguajes, de manera sincrónica y asincrónica. }\end{array}$ & 5.37 & 0.78 & 5.53 & 0.68 \\
\hline $\begin{array}{l}\text { Pedagógica: Fortalecer los procesos de enseñanza y aprendizaje, reco- } \\
\text { nociendo alcances y limitaciones de la incorporación de las TIC a la for- } \\
\text { mación integral de los estudiantes y a su propio desarrollo profesional. }\end{array}$ & 5.57 & 0.71 & 5.28 & 0.90 \\
\hline $\begin{array}{l}\text { Gestión: Utilizar las TIC en la planificación, organización, administración } \\
\text { y evaluación de manera efectiva de los procesos educativos, tanto a nivel } \\
\text { de prácticas pedagógicas como de desarrollo institucional. }\end{array}$ & 5.21 & 0.89 & 5.08 & 0.87 \\
\hline $\begin{array}{l}\text { Investigación: Utilizar las TIC para la transformación del saber y la gene- } \\
\text { ración de nuevos conocimientos. }\end{array}$ & 5.35 & 0.94 & 5.36 & 0.72 \\
\hline TOTAL & 5.36 & 0.67 & 5.54 & 0.74 \\
\hline \multicolumn{5}{|l|}{ Competencias y estándares TIC para la profesión docente (Chile) } \\
\hline $\begin{array}{l}\text { Pedagógica: Incluye la competencia del docente para integrar TIC en la } \\
\text { implementación de ambientes y experiencias de aprendizaje, facilitando } \\
\text { el aprendizaje operativo de sistemas electrónicos y de comunicación } \\
\text { mediada, a partir del aprendizaje de estrategias de búsqueda, selección } \\
\text { y almacenamiento de recursos de información disponibles en sistemas } \\
\text { electrónicos. }\end{array}$ & 5.51 & 0.77 & 5.48 & 0.76 \\
\hline $\begin{array}{l}\text { Técnica o instrumental: Esa dimensión está más relacionada con el com- } \\
\text { ponente tecnológico de la competencia digital, sobre cómo el docente es } \\
\text { capaz de usar el software y herramientas de productividad para la gestión } \\
\text { curricular y para otras tareas docentes, así como sistemas electrónicos } \\
\text { para buscar y procesar información y para comunicarse con los diversos } \\
\text { miembros de la comunidad educativa, conforme a las características del } \\
\text { medio escogido. }\end{array}$ & 5.16 & 0.85 & 5.17 & 0.89 \\
\hline $\begin{array}{l}\text { De gestión: Trata sobre el uso de las TIC para mejorar y renovar procesos } \\
\text { de gestión curricular y de gestión institucional. }\end{array}$ & 5.13 & 0.86 & 4.97 & 0.92 \\
\hline $\begin{array}{l}\text { Social, ética y legal: El docente en esta dimensión es competente cuando } \\
\text { es capaz de integrar las TIC para promover el desarrollo de habilidades } \\
\text { sociales, nuevas formas de socialización y el desarrollo de ciudadanía } \\
\text { digital, usándolas conforme a prácticas que favorezcan el respeto a la di- } \\
\text { versidad, igualdad de trato, y condiciones saludables en el acceso y uso. } \\
\text { Así mismo, es capaz de favorecer el cumplimiento de las normas éticas y } \\
\text { legales. }\end{array}$ & 5.30 & 0.90 & 5.34 & 0.82 \\
\hline
\end{tabular}




\begin{tabular}{lcccc}
\hline MARCO COMPETENCIAL & No Univ. & \multicolumn{2}{c}{ Univ. } \\
\hline $\begin{array}{l}\text { Marco europeo de competencia digital del profesorado (Unión Euro- } \\
\text { pea) }\end{array}$ & M & D.t. & M & D.t. \\
\hline $\begin{array}{l}\text { Desarrollo y responsabilidad social: Desarrollo y responsabilidad profesio- } \\
\text { nal. Aquí se trata de usar las TIC en las actividades de formación continua }\end{array}$ & 5.39 & 0.87 & 5.38 & 0.76 \\
y de desarrollo profesional, participando en comunidades de aprendizaje \\
presencial o virtual, así como de reflexionar sobre los resultados del uso y \\
manejo de las TIC en el propio desarrollo profesional, diseñando e imple- \\
mentando acciones de mejora.
\end{tabular}

El análisis de las puntuaciones alcanzadas indica tres aspectos fundamentales:

1. En todos los marcos, y en las competencias que los conforman, las puntuaciones medias son muy elevadas, tanto para su aplicación en el contexto universitario como no universitario, lo que denota las altas percepciones de los jueces.

2. Las bajas desviaciones típicas indican un fuerte acuerdo entre la diversidad de las respuestas de los jueces.

3. Se observa una cierta similitud entre las puntuaciones que asignaron los jueces que valoraron los marcos para su adecuación al contexto universitario como los que los valoraron para el contexto no universitario.

Con el objeto de conocer si existían diferencias significativas en las valoraciones efectuadas por los expertos sobre la adecuación de los marcos de CDD para su adecuación a los profesores que trabajan en contextos no universitarios y universitarios, formulamos las siguientes hipótesis:

- H0 (hipótesis nula): No existen diferencias significativas entre las valoraciones efectuadas por los expertos para los marcos de CDD para docentes universitarios y docentes no universitarios, con un riesgo alfa de equivocarnos del 0.05.

- H1 (hipótesis alternativa): Existen diferencias significativas entre las valoraciones efectuadas por los expertos para los marcos de CDD para docentes universitarios y docentes no univer- sitarios, con un riesgo alfa de equivocarnos del 0.05 .

Para ello la prueba estadística que utilizamos es la prueba de Kruskal-Wallis para muestras independientes (Siegel, 1976), así como la D de Cohen (1988), para analizar el tamaño de los efectos, en el caso de que sea rechazada alguna $\mathrm{H} 0$.

Por lo que se refiere a los marcos percibidos de forma general, en la Tabla 3 se presentan los valores chi-cuadrado de Kruskal-Wallis y el nivel de significación de la $\mathrm{H} 0$, para un grado de libertad.

\section{Tabla 3. Valores Kruskal-Wallis para el análisis de diferencias en los marcos competenciales}

\begin{tabular}{|c|c|c|}
\hline Marco & $\begin{array}{c}\text { Krus- } \\
\text { kal-Wallis }\end{array}$ & Sig. \\
\hline $\begin{array}{l}\text { Marco europeo de competencia digital } \\
\text { del profesorado (Unión Europea) }\end{array}$ & .038 & .846 \\
\hline $\begin{array}{l}\text { Marco de la International Society for } \\
\text { Technology in Education (ISTE) para } \\
\text { docentes }\end{array}$ & .565 & .452 \\
\hline $\begin{array}{l}\text { Marco UNESCO de Competencia TIC } \\
\text { para Docentes }\end{array}$ & 1.698 & .193 \\
\hline $\begin{array}{l}\text { Marco común de competencia digital } \\
\text { docente del Instituto Nacional de Tec- } \\
\text { nología Educativa y de Formación del } \\
\text { Profesorado (INTEF) }\end{array}$ & 1.512 & .219 \\
\hline $\begin{array}{l}\text { Marco de enseñanza digital del Reino } \\
\text { Unido }\end{array}$ & .236 & .627 \\
\hline $\begin{array}{l}\text { Competencias TIC para el desarrollo } \\
\text { profesional docente del Ministerio de } \\
\text { Educación Nacional de Colombia }\end{array}$ & .000 & .999 \\
\hline $\begin{array}{l}\text { Competencias y estándares TIC para la } \\
\text { profesión docente (Chile) }\end{array}$ & .245 & .620 \\
\hline
\end{tabular}


Como se observa, los valores Kruskal-Wallis alcanzados no permiten rechazar ninguna de las $\mathrm{H} 0$ formuladas al nivel de $p \leq .05$, lo que sugiere que no han existido diferencias en las valoraciones realizadas por los jueces para cada marco, entendidos de forma global, para su adecuación a la adquisición de competencias digitales docentes por profesores de contextos universitarios y no universitarios.
Realizado el análisis para los marcos generales, pasaremos a analizar si hay diferencias significativas en cada una de las competencias que incorpora cada marco. De nuevo utilizaremos el estadístico de Kruskal-Wallis para la aceptación o rechazo de la H0, que se referirá a la no existencia de diferencias significativas (Tabla 4).

Tabla 4. Valores Kruskal-Wallis para el análisis de diferencias en las competencias que conforman los marcos competenciales

\begin{tabular}{|c|c|c|}
\hline MARCO COMPETENCIAL & K-W & Sig. \\
\hline \multicolumn{3}{|c|}{ Marco europeo de competencia digital del profesorado (Unión Europea) } \\
\hline Compromiso profesional & 0.421 & 0.516 \\
\hline Recursos digitales & 0.002 & 0.962 \\
\hline Pedagogía digital & 0.1 & 0.752 \\
\hline Evaluación y retroalimentación & 0.283 & 0.595 \\
\hline Empoderar a los estudiantes & 0.357 & 0.55 \\
\hline Facilitar la competencia digital de los estudiantes & 1.371 & 0.242 \\
\hline \multicolumn{3}{|l|}{ Estándares ISTE para docentes } \\
\hline Aprendices & 0.128 & 0.72 \\
\hline Líderes & 1.009 & 0.315 \\
\hline Ciudadanos & 0.214 & 0.644 \\
\hline Colaboradores & 0.288 & 0.592 \\
\hline Diseñadores & 0.415 & 0.519 \\
\hline Facilitadores & 0.519 & 0.471 \\
\hline Analistas & 0.032 & 0.857 \\
\hline \multicolumn{3}{|l|}{ Marco UNESCO de Competencia TIC para Docentes } \\
\hline Comprender las TIC en la política educativa & 0.773 & 0.379 \\
\hline Currículo y evaluación & 2.607 & 0.106 \\
\hline Pedagogía & 1.037 & 0.309 \\
\hline Aplicación de habilidades digitales & 0.685 & 0.408 \\
\hline Organización y administración & 0.234 & 0.629 \\
\hline Aprendizaje profesional & 1.366 & 0.242 \\
\hline \multicolumn{3}{|c|}{ Marco común de competencia digital docente del INTEF (España) } \\
\hline Información y alfabetización informacional & 0.605 & 0.437 \\
\hline Comunicación y colaboración & 0.084 & 0.772 \\
\hline Creación de contenidos digitales & 1.501 & 0.22 \\
\hline Seguridad & 3.023 & 0.082 \\
\hline Resolución de problemas & 1.553 & 0.213 \\
\hline \multicolumn{3}{|l|}{ Marco de enseñanza digital (Reino Unido) } \\
\hline Planificación pedagógica & 1.667 & 0.197 \\
\hline
\end{tabular}




\begin{tabular}{lcc}
\hline MARCO COMPETENCIAL & K-W & Sig. \\
\hline Enfoque pedagógico & 1.847 & 0.174 \\
\hline Empleabilidad del alumnado & 2.096 & 0.148 \\
\hline Enseñanza específica & 0.032 & 0.859 \\
\hline Evaluación & 0.053 & 0.818 \\
\hline Accesibilidad e inclusión & 1.096 & 0.295 \\
\hline Autodesarrollo & 0.023 & 0.88 \\
\hline Competencias TIC para el desarrollo profesional docente (Colombia) & & 0.727 \\
\hline Tecnológica & 0.121 & 0.162 \\
\hline Comunicativa & 1.952 & 0.794 \\
\hline Pedagógica & 0.068 & 0.31 \\
\hline Gestión & 1.029 & 0.811 \\
\hline Investigación & 0.057 & \\
\hline Competencias y estándares TIC para la profesión docente (Chile) & & 0.708 \\
\hline Pedagógica & 0.14 & 0.872 \\
\hline Técnica o instrumental & 0.026 & 0.173 \\
\hline De gestión & 1.853 & 0.914 \\
\hline Social, ética y legal & 0.012 & 0.648 \\
\hline Desarrollo y responsabilidad social & 0.208 & \\
\hline
\end{tabular}

Los valores obtenidos no permiten rechazar ninguna de las H0. En consecuencia, se puede afirmar con un $95 \%$ de significatividad que tampoco, por las dimensiones que conforman los marcos competenciales, los docentes han discriminado diferencias entre la adecuación de esta para la adquisición de CDD en contextos universitarios y no universitarios.

\section{Conclusiones, discusión y limitaciones del estudio}

El trabajo permite obtener una serie de conclusiones. La primera es que los diferentes marcos, y competencias que se incorporan dentro de los mismos, han sido puntuados positivamente por jueces de diferentes niveles educativos, así como por personal técnico. Ello lleva a señalar que son propuestas bien consolidadas y que sirven para indicar a los docentes, universitarios o no universitarios, las competencias digitales que deben adquirir para el desempeño de su actividad profesional. Al mismo tiempo, se confirman las valoraciones que diferentes autores han ido realizando respecto a que los marcos presenta- dos son los que poseen mayor significación desde una perspectiva internacional (Cabero \& Martínez, 2019; Cabero \& Palacios, 2020; Durán et al., 2016; Lázaro-Cantabrana et al., 2019; Marín, 2017; Padilla-Hernández et al., 2019; Prendes \& Gutiérrez, 2013; Rodríguez-García et al., 2019; Silva et al., 2019).

Otro de los aportes del trabajo permite también señalar que no ha existido discriminación en los marcos por parte de los jueces; dicho de otra forma, los jueces, tanto los que evaluaron los marcos competenciales referidos a la capacitación de docentes no universitarios como universitarios, valoraron de forma significativa las diferentes propuestas, y no existieron diferencias entre ellos.

El estudio presenta una serie de limitaciones que abren al mismo tiempo líneas futuras de investigación que deben ser contempladas. Por una parte, hay que indicar que, aunque se ha utilizado un proceso muy concienzudo para la selección de los expertos, siempre queda la duda de la significación de su elección. Y, por otra, que el no haber encontrado dife- 
rencias pudiera deberse a la poca presencia de jueces que no han trabajado en los niveles no universitarios, o que se ha trabajado con muestras independientes de jueces. Lo comentado últimamente lleva a una propuesta de una nueva investigación referida a que sean los mismos jueces los que pudieran evaluar las propuestas para ambos niveles, aunque ello implicaría mayor esfuerzo para ellos. También se sugiere realizar investigaciones de corte similar sobre los rasgos específicos de la enseñanza en cada disciplina o materia, tanto universitaria como no universitaria. De la misma forma, como prospectiva de futuro, los resultados de esta investigación pueden ser utilizados para orientar a los docentes en el reconocimiento y desarrollo efectivo de las competencias digitales para el aprovechamiento de las TIC en procesos de formación. Además, se podría consolidar una posible estrategia de apropiación de competencias digitales para docentes de acuerdo con la valoración de los expertos.

\section{Financiación}

El presente artículo es parte del proyecto Diseño, producción y evaluación de tMOOC para la adquisición por los docentes de competencias digitales docentes (RTI2018-097214-B-C31) financiado por el Ministerio de Ciencia, Innovación y Universidades (España).

El presente artículo es parte del proyecto Diseño, producción y evaluación de tMOOC para la adquisición de competencias digitales del profesorado universitario. Consejería de Economía y Consentimiento de la Junta de Andalucía (US-1260616).

\section{Referencias bibliográficas}

Blau, I., \& Shamir-Inbal, T. (2017). Digital competences and long-term ICT integration in school culture: The perspective of elementary school leaders. Education and Information Technologies, 22(3), 769787.

https://doi.org/10.1007/s10639-015-9456-7

Butcher, N. (2019). Marco de competencias docentes en materia de TIC UNESCO. París: UNESCO.
Cabero, J., \& Barroso, J. (2013). La utilización del juicio de experto para la evaluación de TIC: el Coeficiente de competencia experta. Bordón. Revista de Pedagogía, 65(2), 25-38.

Cabero, J., \& Infante, A. (2014). Empleo del método Delphi y su empleo en la investigación en comunicación y educación. Edutec. Revista Electrónica de Tecnología Educativa, 48.

Cabero, J., \& Llorente, M. C. (2013), La aplicación del juicio de experto como técnica de evaluación de las tecnologías de la información (TIC). Eduweb. Revista de Tecnología de Información y Comunicación en Educación, 7(2), 11-22.

Cabero, J., \& Martínez, A. (2019). Las tecnologías de la información y comunicación y la formación inicial de los docentes. Modelos y competencias digitales. Profesorado. Revista de Curriculum y Formación del Profesorado, 23(3), 247-268.

Cabero-Almenara, J., \& Palacios-Rodríguez, A. (2020). Marco Europeo de Competencia Digital Docente «DigCompEdu». Traducción y adaptación del cuestionario «DigCompEdu Check-In». EDMETIC, 9(1), 213-234.

https://doi.org/10.21071/edmetic.v9i1.12462

Campo-Saavedra, M. F., Segovia-de-Cabrales, R., Martínez-Barrios, P., Rendón-Osorio, H. J., \& Calderón-Rodríguez, G. C. (2013). Competencias TIC para el desarrollo profesional docente. Bogotá: Ministerio de Educación Nacional.

Carretero, S., Vuorikari, R., \& Punie, Y. (2017). DigComp 2.1: The Digital Competence Framework for Citizens With eight proficiency levels and examples of use. Luxembourg: Publication Office of the European Union. https://doi.org/10.2760/38842

Casillas, M., \& Ramírez, A. (2019). Cultura digital y cambio institucional de las universidades. Revista de la Educación Superior, 48(191), 97-111.

Cohen, J. (1988). Statistical Power Analysis for the Behavioral Sciences (2nd ed.). Hillsdale, NJ: Lawrence Erlbaum Associates, Publishers. 
Consejo de la Unión Europea. (2006). Recomendación del Parlamento Europeo y del Consejo de 18 de diciembre de 2006 sobre las competencias clave para el aprendizaje permanente. Bruselas: Diario Oficial de la Unión Europea.

Consejo de la Unión Europea. (2018). Recomendación del Consejo, de 22 de mayo de 2018, relativa a las competencias clave para el aprendizaje permanente. Bruselas: Diario Oficial de la Unión Europea.

Crompton, H. (2017). ISTE Standards for Educators: A Guide for Teachers and Other Professionals. Eugene (Oregon, Estados Unidos): International Society for Technology in Education.

Cuartero, M., Espinosa, M., \& Porlán, I. (2019). Certificación de la Competencia Digital Docente: propuesta para el profesorado universitario. RIED. Revista Iberoamericana de Educación a Distancia, 22(1), 187-205.

https://doi.org/10.5944/RIED.22.1.22069

Durán, M., Gutiérrez, I., \& Prendes, M. P. (2016). Análisis conceptual de modelos de competencia digital del profesorado universitario. Relatec. Revista Latinoamericana de Tecnología Educativa, 15(1), 97-114.

Education and Training Foundation. (2019). Digital Teaching Professional Framework. Taking Learning to the Next Level. London: JISC.

Elliot, J., Gorichon, S., Irigoin, M., \& Maurizi, M. (2011). Competencias y Estándares TIC para la Profesión Docente. Santiago: Ministerio de Educación.

Ferrari, A. (2013). DIGCOMP: A Framework for Developing and Understanding Digital Competence in Europe. Luxembourg: Publications Office of the European Union. https://doi.org/10.2788/52966

Flores-Lueg, C., \& Roig-Vila, R. (2016). Diseño y validación de una escala de autoevaluación de competencias digitales para estudiantes de pedagogía. PixelBit, Revista de Medios y Educación, 12(48), 209-224. https://doi.org/10.12795/pixelbit.2016.i48.14

Galicia, L., Balderrama, J., \& Edel, R. (2017). Vali- dez de contenido por juicio de expertos: propuesta de una herramienta virtual. Apertura, 9(2), 42-53. http://dx.doi.org/10.18381/Ap.v9n2.993

Ghomi, M., \& Redecker, C. (2018). Digital Competence of Educators (DigCompEdu): Development and Evaluation of a Self-Assessment Instrument for Teachers' Digital Competence. Berlin: Joint Research Center.

Gil, J., Rodríguez, G., \& García, E. (1995). Estadística básica aplicada a las Ciencias de la Educación. Sevilla: Kronos.

Gutiérre-Castillo, J. J., Cabero-Almenara, J., \& Estrada-Vidal, L. I. (2017). Diseño y validación de un instrumento de evaluación de la competencia digital del estudiante universitario. Espacios, 38(10).

Hernández-Suárez, C. A. (2016). Competencias TIC para el desarrollo profesional docente en educación básica. Praxis y Saber, 7(14), 41-69.

https://doi.org/10.19053/22160159.5217

Instituto Cervantes. (2002). Marco Común Europeo de Referencia para las Lenguas: aprendizaje, enseñan$z a$, evaluación. Madrid: Instituto Cervantes.

INTEF. (2013). Marco Común de Competencia Digital Docente. Borrador con propuesta de descriptores V1.0. Madrid: Instituto Nacional de Tecnologías Educativas y Formación del Profesorado.

INTEF. (2014). Marco Común de Competencia Digital Docente V2.0. Madrid: Instituto Nacional de Tecnologías Educativas y Formación del Profesorado.

INTEF. (2017a). Marco Común de Competencia Digital Docente. Enero 2017. Madrid: Instituto Nacional de Tecnologías Educativas y Formación del Profesorado.

INTEF. (2017b). Marco Común de Competencia Digital Docente. Octubre 2017. Madrid: Instituto Nacional de Tecnologías Educativas y Formación del Profesorado.

ISTE. (2018). Crosswalk: Future Ready Librarians Framework and ISTE Standards for Educators. Washington D.C.: International Association for Technology in Education. 
Joint Research Centre. (2018). DigComp into action, get inspired make it happen. A user guide to the European Digital Competence framework. European Commission. https://doi.org/10.2760/112945

Kullaslahti, J., Ruhalahti, S., \& Brauer, S. (2019). Professional development of digital competences: Standardized frameworks supporting evolving digital badging practices. Journal of Siberian Federal University - Humanities and Social Sciences, 12(2), 175186. https://doi.org/10.17516/1997-1370-0387

Landeta, J. (2002). El método Delphi: una técnica de previsión del futuro. Barcelona: Ariel.

Lázaro-Cantabrana, J., Usart-Rodríguez, M., \& Gisbert-Cervera, M. (2019). Assessing Teacher Digital Competence: the Construction of an Instrument for Measuring the Knowledge of Pre-Service Teachers. Journal of New Approaches in Educational Research, 8(1), 73-78.

https://doi.org/doi:10.7821/naer.2019.1.370

López-Gómez, E. (2018). El método Delphi en la investigación actual en educación: una revisión teórica y metodológica. Educación $X X 1,21(1), 17-40$, https://doi.org/doi: 110.5944/educXX1.15536

Malla, F., \& Zabala, I. (1978). La previsión del futuro en la empresa (III): el método Delphi. Estudios Empresariales, 39, 13-24.

Marín, V. (2017). Diseño y evaluación de un instrumento de competencia digital docente. [Tesis doctoral no publicada]. Universidad de las Islas Baleares.

Martínez, E., Travieso, N., Sagaró, N., Urbina, O., \& Martínez-Ramírez, I. (2018). Identificación de las competencias específicas de los profesionales de enfermería en la atención al neonato en estado grave. Medisan, 22(2), 184-192.

McCloskey, E. M. (2012). Docentes globales: un modelo para el desarrollo de la competencia intercultural on-line. Global Teachers: A Model for Building Teachers' Intercultural Competence Online. Comunicar, 19(38), 41-49.

https://doi.org/10.3916/C38-2011-02-04
Mishra, P., Koehler, M. J., \& Bragg, W. H. (2006). Technological Pedagogical Content Knowledge: A Framework for Teacher Knowledge The advent of digital technology has dramatically changed routines and practices in most arenas of human work. Advocates of technology in education often envisage similar dramatic changes in the process of teaching. Teachers College Record, 108(6), 1017-1054.

Moreno-Rodríguez, M. D., Gabarda-Méndez, V. G., \& Rodríguez-Martí, A. M. (2018). Alfabetización informacional y competencia digital en estudiantes de magisterio. Profesorado, Revista de Currículum y Formación del Profesorado, 22(3), 253-270.

https://doi.org/10.30827/PROFESORADO.V22I3.8001

Padilla-Hernández, A. L., Gámiz-Sánchez, V. M., \& Romero-López, M. A. (2019). Niveles de desarrollo de la competencia digital docente: una mirada a marcos recientes del ámbito internacional. INNOEDUCA. International Journal of Technology And Educational Innovation, 5(2), 140-150.

https://doi.org/DOI:10.24310/innoeduca.2019. v5i2.5600

Pérez-Escoda, A., García-Ruiz, R., \& Aguaded, I. (2019). Dimensions of digital literacy based on five models of development. Cultura y Educación, 31(2), 232-266.

https://doi.org/10.1080/11356405.2019.1603274

Porat, E., Blau, I.,\& Barak, A. (2018). Measuring digital literacies: Junior high-school students' perceived competencies versus actual performance. Computers y Education, 126(2), 23-36.

https://doi.org/10.1016/J.COMPEDU.2018.06.030

Prendes, M. P., \& Gutiérrez, I. (2013). Competencias tecnológicas del profesorado en las universidades españolas. Revista de Educación, 361, 196-222.

https://doi.org/DOI:10.4438/1988-592XRE-2011-361-140

Redecker, C., \& Punie, Y. (2017). Digital Competence of Educators DigCompEdu. Luxembourg: Publications Office of the European Union. 


\section{Revista Caribeña de Investigación Educativa | 2020, 4(2), 137-158}

Robles, P., \& Rojas, M. D. C. (2015). La validación por juicio de expertos: dos investigaciones cualitativas en Lingüística aplicada. Revista Nebrija de Lingüistica Aplicada, 18.

http://r.issu.edu.do/l.php?l=229SH9

Rodríguez-García, A. M., Raso-Sánchez, F., \& Ruiz-Palmero, J. R. (2019). Competencia digital, educación superior y formación del profesorado: un estudio de metaanálisis en la Web of Science. PixelBit. Revista de Medios y Educación, 54, 65-81. https://doi.org/10.12795/pixelbit.2019.i54.04

Romero-Martín, R., \& Fraile, A. (2017). Evaluación formativa, competencias comunicativas y TIC en la formación del profesorado. Comunicar, 73-82.

Saavedra, C., Casillas, M., \& Ramírez, A. (2019). Saberes Digitales: un desafío para los maestros de hoy. Revista Electrónica de Investigación e Innovación Educativa, 4(3), 84-91.

Siegel, S. (1976). Estadistica no paramétrica aplicada a las ciencias de la conducta. México: Trillas.

Silva, J., Morales, M., Lázaro, J., \& Gisbert, M. (2019). La competencia digital docente en formación inicial: Estudio a partir de los casos de Chile y
Uruguay. Archivos Analiticos de Politicas Educativas, 27(93). https://doi.org/10.14507/epaa.27.3822

Suárez-Rodríguez, J., Almerich, G., Orellana, N., \& Díaz-García, I. (2018). A basic model of integration of ICT by teachers: competence and use. Educational Technology Research and Development, 66(5), 1165-1187.

https://doi.org/10.1007/s11423-018-9591-0

Vuorikari, R., Punie, Y., Carretero, S., \& Van-denBrande, G. (2016). DigComp 2.0: The Digital Competence Framework for Citizens. Luxembourg: Publication Office of the European Union.

https://doi.org/10.2791/11517

Williamson, B., Potter, J., \& Eynon, R. (2019). New research problems and agendas in learning, media and technology: the editors' wishlist. Learning, $\mathrm{Me}$ dia and Technology, 44(2), 87-91. https://doi.org/10.1080/17439884.2019.1614953

Witkin, B. R., \& Altschuld, J. W. (1995). Planning and conducting needs assessment: A practical guide. Thousand Oaks, CA: Sage. 


\section{CABERO-ALMENARA • ROMERO-TENA • BARROSO-OSUNA • PALACIOS-RODRÍGUEZ}

Marcos de Competencias Digitales Docentes y su adecuación al profesorado universitario...

\section{Anexo}

Preguntas formuladas para obtener el coeficiente de competencia experta.

A) Marque en la casilla que le corresponde el grado de conocimiento que usted posee acerca de temáticas como las siguientes: formación del profesorado en TIC, competencias digitales, alfabetización digital... Valórese en una escala de 0 a 10 (considerando el 0 como no tener absolutamente ningún conocimiento y 10 de pleno conocimiento del estado de la cuestión).

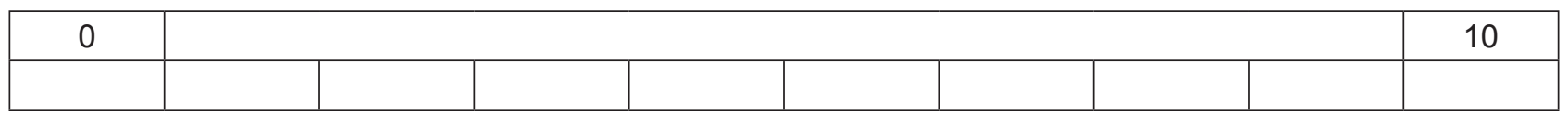

Nota: Se obtiene la puntuación Kc (Coeficiente de conocimiento - valor de 0 a 10).

B) Autoevalúe el grado de influencia que cada una de las fuentes que le presentamos a continuación ha tenido en su conocimiento y criterios sobre el tema de la formación del profesorado en TIC, competencias digitales, alfabetización digital...

\begin{tabular}{|l|c|c|c|}
\hline & BAJO & MEDIO & ALTO \\
\hline Análisis teóricos realizado por usted & 0.3 & 0.2 & 0.1 \\
\hline Su experiencia obtenida de su actividad práctica & 0.5 & 0.4 & 0.2 \\
\hline $\begin{array}{l}\text { Estudio de trabajo sobre el tema, de autores es- } \\
\text { pañoles }\end{array}$ & 0.05 & 0.05 & 0.05 \\
\hline $\begin{array}{l}\text { Estudio de trabajo sobre el tema, de autores ex- } \\
\text { tranjeros }\end{array}$ & 0.05 & 0.05 & 0.05 \\
\hline $\begin{array}{l}\text { Su propio conocimiento acerca del estado del pro- } \\
\text { blema en el extranjero }\end{array}$ & 0.05 & 0.05 & 0.05 \\
\hline Su intuición sobre el tema abordado & 0.05 & 0.05 & 0.05 \\
\hline
\end{tabular}

Nota: Se obtiene la puntuación Ka (Coeficiente de argumentación - valor el sumatorio de las respuestas ofrecidas por el experto).

C) A continuación le vamos a presentar las dimensiones y competencias elaboradas por diferentes instituciones y organizaciones respecto a las competencias digitales que deben poseer los docentes. Le pedimos que las puntúe de acuerdo con su utilidad para formar al profesorado universitario/no universitario (depende del cuestionario).

La escala para la valoración es la siguiente:

1. $\mathrm{MN}=$ Muy negativo / muy en desacuerdo

2. $\mathrm{N}=$ Negativo / En desacuerdo

3. R- = Regular negativo / Moderadamente en desacuerdo 
Revista Caribeña de Investigación Educativa | 2020, 4(2), 137-158

4. $\mathrm{R}+=$ Regular positivo / Moderadamente de acuerdo

5. $\mathrm{P}=$ Positivo / De acuerdo

6. $\mathrm{MP}=$ Muy positivo / Muy de acuerdo

D) Marcos y competencias para evaluar.

\section{CÓMO CITAR:}

Cabero-Almenara, J., Romero-Tena, R., Barroso-Osuna, J., \& Palacios-Rodríguez, A. (2020). Marcos de Competencias Digitales Docentes y su adecuación al profesorado universitario y no universitario. Revista Caribeña de Investigación Educativa (RECIE), 4(2), 137-158. https://doi.org/10.32541/recie.2020.v4i2.pp137-158 